\title{
The effectiveness of the nursing intervention on cholesterol level and quality of life among hypertensive patients with dyslipidemia
}

\author{
Sabah M. Ebrahem*1, Nahid F. El Gahsh², Seham M. Abd-Elalem² \\ ${ }^{1}$ Psychiatric Nursing Department Faculty of Nursing, Menofia University, Egypt \\ ${ }^{2}$ Medical Surgical Nursing Department Faculty of Nursing, Menofia University, Egypt
}

Received: January 16, 2017

DOI: $10.5430 /$ cns.v5n2p32
Accepted: February 26, 2017

Online Published: March 14, 2017

\begin{abstract}
Objective: Hypertension and dyslipidemia are widely recognized a major risk factors for cardiovascular disease (CVD). The aim of this study was to evaluate the effectiveness of the nursing intervention on cholesterol level and quality of life (QOL) among hypertensive patients with dyslipidemia.

Methods: Design: A quasi -experimental pre-post-test design was used to achieve the aim of the study. The study was conducted in the University Hospital at Shebin El-kom District, Menoufia Governorate, Egypt. Purposeful sample of 100 hypertensive patients with dyslipidemia on treatment from the previous mentioned setting. Instruments: (1) structured interview questionnaire to assess socio-demographic data, risk factors of hypertension and dyslipidemia and patient's knowledge about hypertension and dyslipidemia; (2) Physiological measurement to assess blood pressure, weight and cholesterol level; (3) QOL scale to assess healthful lifestyle.

Results: The main findings of the study there was statistically significant improvement of total knowledge related to hypertension and dyslipidemia, and there was statistically significant reduction in blood pressure and cholesterol level post-intervention than pre-intervention.

Conclusions: The nursing intervention has a positive effect on blood pressure, cholesterol level and QOL of hypertensive patients with dyslipidemia.

Recommendations: The nursing intervention that includes of adherence to diet regimen, prescribed medication and performing physical exercise, stress management, assertiveness training should be integrated into medical outpatient clinic to assist patients diagnosed with hypertension to cope with their illness and improve the QOL of hypertensive patients.
\end{abstract}

Key Words: Nursing intervention, Hypertension, Quality of life, Dyslipidemia

\section{INTRODUCTION}

Hypertension is connected to wide range of severe medical disorders including kidney, cardiovascular and cerebrovascular diseases. ${ }^{[1,2]}$ According WHO hypertension in Egypt affecting $38.7 \%$ of males, $40.8 \%$ of females and in total affecting $39.7 \% .^{[3]}$ High prevalence of hypertension is at- tributed to people enlargement, aging and other risk factors, like unhealthy diet, alcohol abuse, physical inactivity, obesity and living in constant stress. The complications of high blood pressure are increased when the patient has other health risk factors such as (tobacco use, obesity, high cholesterol and diabetes mellitus) that increase the odds of heart attack, stroke

${ }^{*}$ Correspondence: Sabah M. Ebrahem; Email: dr.sabah20@gmail.com; Address: Psychiatric Nursing Department Faculty of Nursing, Menofia University, Egypt. 
and kidney failure. ${ }^{[4]}$

Hypertension and dyslipidemia are the main contributing risk factors for cardiovascular disease (CVD) which was increased worldwide particularly in developing countries like India. ${ }^{[5]}$ Dyslipidemia is defined as "abnormal levels of Total Cholesterol (TC) or Low-Density Cholesterol (LDL-C), High-Density Cholesterol (HDL-C) and Triglycerides (TGs) individually or in combination". ${ }^{[6]}$ Cholesterol is a waxy, fatlike substance found in the walls of cells in all parts of the body, from the nervous system to the liver to the heart. The body uses cholesterol to make hormones, bile acids, vitamin D, and other substances. ${ }^{[7]}$

The prevalence of the coexistence of hypertension and dyslipidemia range from $15 \%$ to $31 \% .^{[5]}$ The link between hypertension and dyslipidemias is still not completely understood; dyslipidemias result in atherosclerosis and structural changes that result in the decreased elasticity of large arteries which cause arterial hypertension in the elderly. ${ }^{[8,9]}$ Genetic factors were considered as a predisposing factor to the concomitant occurrence of hypertension and dyslipidemia. ${ }^{[10]}$ WHO classified the risk factors of CVD into non-modifiable risk factors and modifiable risk factors. Non-modifiable risk factors include family history, ethnicity and age which cannot be changed. Modifiable risk factors that can be treated or changed include tobacco exposure, high blood pressure (hypertension), high cholesterol, obesity, physical inactivity, diabetes, unhealthy diet, and harmful use of alcohol. ${ }^{[11]}$

Acute stress may increase a person's risk of CVD. It reduces blood flow to the heart, leads to irregular heart beat and increases the chance of blood clotting. A stressful life event can alter thinking and behavior that also increase the incidence of adopting poor habits like smoking and poor dietary habits. This can negatively affect the blood, nervous system, and heart. There is a strong and consistent link between depression, social isolation, lack social support, abnormal blood lipid levels, smoking, high blood pressure and heart disease. ${ }^{[12]}$

The management of dyslipidemia requires a comprehensive strategy to control lipid levels and to address associated metabolic abnormalities and modifiable risk factors such as "hypertension, diabetes, obesity, and cigarette smoking". The first-line approach to primary prevention in patients with lipid disorders involves the implementation of lifestyle changes, including physical activity and medical nutrition therapy. ${ }^{[13]}$ A therapeutic lifestyle including a healthy diet and increased physical activity can help for weight management and decrease the risk for chronic disease. A healthy diet includes fruits, vegetables, whole grains, lean meats, poultry, seafood, legumes, and low-fat dairy products. In addition to reducing dietary cholesterol, replacing saturated fats with the more heart-healthy fats is desired. Physical activity helps balance calories consumed with calories expended. ${ }^{[14]}$ Treatment may also involve pharmacotherapy, as well as patient education programs, to promote further risk reduction through smoking cessation and weight loss. ${ }^{[13]}$ Nursing interventions that include a program that focuses on diet, physical exercise, decreasing weight, smoking cessation, controlling high blood pressure and stress management are needed to manage dyslipidemia. ${ }^{[15]}$

\section{Significance of the study}

According to $\mathrm{WHO}$, the highest prevalence of hypertension was found in Africa $46 \%$, while the lowest prevalence was found in the Americas 35\%. ${ }^{[16]}$ Worldwide the treatment of hypertension remains a challenge beyond programs aimed at the prevention and treatment of hypertension. More studies are needed to reduce complications that are developed from hypertension and dyslipidemia through adherence to pharmacological treatments and application of nursing intervention programs that include uses of a healthy diet, physical activity and stress management for improving the quality of life (QOL). The current study aimed to evaluate the effectiveness of the nursing intervention on cholesterol level and QOL among hypertensive patients with dyslipidemia.

The risk of developing CVD increased when the TC level increased in patients with hypertension and dyslipidemia. Controling this condition needs both nutritional and pharmacological management. ${ }^{[17]}$ In addition to pharmacological treatment updating lifestyle guidelines are recommended to achieve both primary and secondary prevention of CVD. These lifestyle guidelines amied to modify low-density lipoprotein (LDL) and blood pressure. ${ }^{[5,18]}$

\subsection{Aim of the study}

The aim of this study was to evaluate the effectiveness of the nursing intervention on cholesterol level and QOL among hypertensive patients with dyslipidemia.

\subsection{Operational definition}

- The serum TC can be operationally defined by the total mean score of serum TC obtained from the patient's medical record (lab results)

- The QOL can be operationally defined by the total mean score of QOL scale developed by Padilla and Grant $^{[19]}$

- Persons were considered hypertensive if they meet one of the following conditions:

1) Diastolic blood pressure (DBP) greater than or equal to $90 \mathrm{mmHg}$. 
2) Systolic blood pressure (SBP) greater than or equal to $140 \mathrm{mmHg}$.

3) Currently taking antihypertensive medications regardless of their actual BP measurement

\subsection{Research hypothesis}

(1) The intervention program has a significant effect on improving the mean score of the QOL;

(2) The intervention program has a significant effect on reducing the mean score of cholesterol level;

(3) The intervention program has a significant effect on improving the blood pressure.

\section{Methodology}

\subsection{Research design}

Quasi-experimental research design (one group pre-/posttest) was utilized to achieve the aim of the study.

\subsection{Research setting}

The study was conducted in the University Hospital at Shebin El-kom District, Menoufia Governorate, Egypt.

\subsection{Subjects}

A purposeful sample of 100 hypertensive patients with dyslipidemia on medical treatment in University Hospital at Shebin El-kom District, Menoufia Governorate, Egypt. Inclusion criteria were conscious adult patients who had hypertension with dyslipidemia from both genders and on medical treatment. Exclusion criteria were patients who had a history of psychiatric disorders or other medical conditions as patients such as heart failure, renal failure, and diabetes.

\subsection{Instruments of the study}

Instrument (1): A structured Interviewing questionnaire was developed by the researcher after reviewing the related literature and consisted of three parts:

Part I: sociodemographic data including patient's age, gender, the level of education, occupation, marital status.

Part II: Questions to assess risk factors of hypertension and dyslipidemia including heredity factors, smoking, eating fatty foods, salt in the diet, and depression.

Part III: Twelve questions to assess patient's knowledge about hypertension and dyslipidemia that contain definition, causes, signs and symptoms, complications, treatment, side effects of treatment and foods that increase and decrease cholesterol level.

Scoring system: The responses were classified as completely correct, incompletely correct, and incorrect answer. Each item in the sheet was given a score of two marks for the complete correct answer, one mark for the incomplete correct answer and zero for the incorrect answer. Then the score was summed up and divided into three categories: a score range from $65 \%$ to $100 \%$ (from 16 to 24 ) illustrated that patients have good knowledge; while a score of $50 \%$ to less than $65 \%$ (from 12 to less than 16) illustrated fair and a score less than $50 \%$ (less than 12) illustrated that patients have poor knowledge.

Instrument (2): Physiologic Assessment: Physiological measurements that included blood pressure, weight and laboratory investigations for lipid profile that include Serum Cholesterol (total) normal value less than $200 \mathrm{mg} / \mathrm{dl}$, Serum TGs (less than $150 \mathrm{mg} / \mathrm{dl}$ ), Serum LDL Cholesterol (less than $100 \mathrm{mg} / \mathrm{dl}$ ), Serum HDL Cholesterol (optimal more than 65 $\mathrm{mg} / \mathrm{dl}$ and close to optimal $35-65 \mathrm{mg} / \mathrm{dl}$ ).

Instrument (3): QOL scale: This scale was adopted from Padilla and Grant ${ }^{[19]}$ to assess healthful lifestyle, and was translated into Arabic by Kandel. ${ }^{[20]}$ The scale consisted of 41 questions rated on a 10 point rating scale, giving the total score 410 . These questions covered the following four dimensions; physical pattern (21 questions); psychological pattern (8 questions), recreational pattern (6 questions), and spiritual wellbeing (6 questions).

\subsection{Scoring system}

Regarding physical pattern: less than 84 - low, 85 to 168 moderate, and from 169 to 210 - high. Regarding psychological pattern: less than 32 - low, 32 to 64 - moderate, and from 65 to 80 - high . Regarding recreational pattern: less than 24 - low, 25 to 48 - moderate, and from 49 to 60 - high. Regarding spiritual pattern: less than 24 - low, 25 to 48 moderate, and from 49 to 60 - high. Regarding total QOL: less than 164 - low, 165 to 328 - moderate, and from 329 to 410 - high.

\subsubsection{Reliability}

The tools used in this study were tested for its reliability using test-retest reliability and proved to be strongly reliable at .85 for tool one and at .91 for tool three.

\subsubsection{Validity of the tools}

The tools for data collection were tested for content validity by a panel of experts in medical and psychiatric health nursing specialties to ascertain relevance and completeness. Required modifications were carried out accordingly.

\subsection{Procedure of data collection}

\subsubsection{Preparatory phase}

Review of relevant literature was carried out to get a clear picture of all aspects of the research topic and variables to 
design the data collection tools.

Administrative approval: An official permission was obtained from the Manager of the University Hospital at Shebin El-kom District, Menoufia Governorate.

Pilot study: Before starting data collection a pilot study was carried out on 10 patients, to assess the clarity, applicability and time needed to complete the research instruments. The necessary modifications were carried out as determined from the pilot study. The sample used for the pilot study was excluded from the total sample.

Ethical considerations: Protection of human rights was emphasized to the patients and participation was voluntary. Anonymity and confidentiality of the responses were respected. The patients had the full right to refuse to participate in the study or withdrawal at any time.

\subsubsection{Implementation phase}

(1) Fieldwork: the data was collected over four months, all subjects who met the inclusion criteria were included in the research and a comfortable, private place was chosen for the interview. Each subject was interviewed individually at the outpatient clinic where the pre-assessment was done using the instruments for data collection. Then the subjects were divided into 8 groups ranging from 12 to 13 patients in each group to attend 8 sessions, two sessions per week, every session taking one hour.

(2) The nursing intervention: The nursing intervention was developed and given during eight sessions. The general and specific objectives were achieved through several teaching methods such as brain-storming, lecture, discussion, and handouts, and the use of illustrated media (video, pictures, and computer programs). At the end of each session time was allotted for asking questions, giving feedback, and explaining homework assignments for the next session.

The intended learning outcome objectives (ILOS) for the nursing intervention program sessions were:

- Define dyslipidemia

- Identify causes and risk factors of dyslipidemia

- Enumerate the general signs and symptoms of high cholesterol level

- List the different treatment regimens for patients having high cholesterol level

- Understand the healthy lifestyle changes

- Apply stress management techniques

- Apply assertiveness training

The sessions for intervention were:

Session 1: This session was concerned with open discussion to identify, integrate the group, clarify the aim of the

Published by Sciedu Press timetable allowed for interventions, and completing the pre-test.

Session 2: This session was concerned with ascertaining knowledge about definitions and causes of dyslipidemia, precipitating factors of dyslipidemia, and high cholesterol levels.

Session 3: This session focused on healthy lifestyle habits and the role of nutrition and exercises in reducing cholesterol levels.

Session 4, 5 and 6: This session was concerned with the application of stress management techniques.

Session 7 and 8: This session was concerned with the application of assertiveness training and emotional expression.

\subsubsection{Evaluation phase}

The researcher interviewed the patients for evaluation of the nursing program after three months by using post-assessment instruments.

\subsection{Data processing and analysis}

Data were analyzed using the IBM Statistical Package of Social Science (SPSS) version 16. Descriptive and analytical procedures were performed. The tests of significance included; Chi-square $\left(\chi^{2}\right)$ and paired sample $t$-test. A $p$-value of $>.05$ was considered statistically non-significant, a $p$-value of $<05$ was considered statistically significant, and a $p$-value of $<.001$ was considered statistically highly significant.

\section{RESUlts}

Table 1 illustrates that the more than half of the subjects were female $60 \%$ and came from a rural region (58\%) with a mean age of $36.21 \pm 4.96$ years. Seventy-one percent were married and about one-third of the subjects (31\%) had secondary education. More than half of the subjects (52\%) did not have enough family income and about half (47) were governmental employees.

Table 2 shows that there is a highly statistical significant reduction in all risk factors for hypertension and dyslipidemia (eating fatty foods, smoking, the amount of salt in patient's diet, depression) from pre-intervention to post-intervention. This indicated that the nursing intervention improved the patient's lifestyle and improved the symptoms of depression.

Figure 1 illustrates that only about $11 \%$ of the subjects presented good knowledge related to hypertension and dyslipidemia before the nursing intervention which improved to (49\%) after nursing intervention with a highly statistically significant difference at $p=.000$. 
Table 1. Socio-demographic characteristics of the studied subjects

\begin{tabular}{|c|c|c|}
\hline \multirow{2}{*}{ Sociodemographic Data } & \multicolumn{2}{|c|}{ Study group $(\mathrm{N}=100)$} \\
\hline & $\mathbf{N}$ & $\%$ \\
\hline \multicolumn{3}{|l|}{ Age (years): } \\
\hline - $40-$ & 18 & 18 \\
\hline - $50-$ & 56 & 56 \\
\hline - $\geq 50$ & 26 & 26 \\
\hline$X \pm S D$ & $36.21 \pm 4.96$ & \\
\hline \multicolumn{3}{|l|}{ Gender: } \\
\hline - Male & 40 & 40 \\
\hline - Female & 60 & 60 \\
\hline \multicolumn{3}{|l|}{ Marital status: } \\
\hline - Single & 14 & 14 \\
\hline - Married & 71 & 71 \\
\hline - Divorced & 8 & 8 \\
\hline - Widow & 7 & 7 \\
\hline \multicolumn{3}{|l|}{ Residence: } \\
\hline - Urban & 42 & 42 \\
\hline - Rural & 58 & 58 \\
\hline \multicolumn{3}{|l|}{ Educational level: } \\
\hline - Illiterate & 19 & 19 \\
\hline - Read and write & 11 & 11 \\
\hline - Primary education & 13 & 13 \\
\hline - Secondary education & 31 & 31 \\
\hline - Higher education & 26 & 26 \\
\hline \multicolumn{3}{|l|}{ Family Income: } \\
\hline - Enough & 48 & 48 \\
\hline - Not enough & 52 & 52 \\
\hline \multicolumn{3}{|l|}{ Occupation: } \\
\hline - Manual work & 17 & 17 \\
\hline - Employee & 47 & 47 \\
\hline - Technical work & 17 & 17 \\
\hline - House wife & 19 & 19 \\
\hline
\end{tabular}

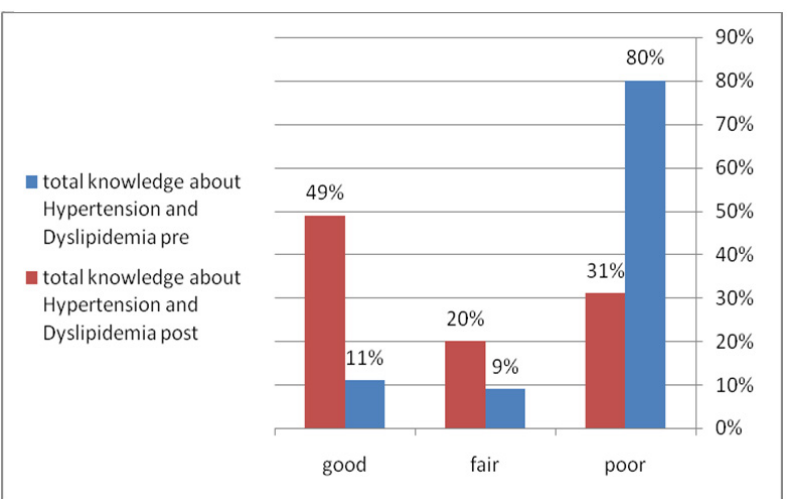

Figure 1. Knowledge of the studied subjects pre-intervention to post-intervention related to hypertension and dyslipidemia

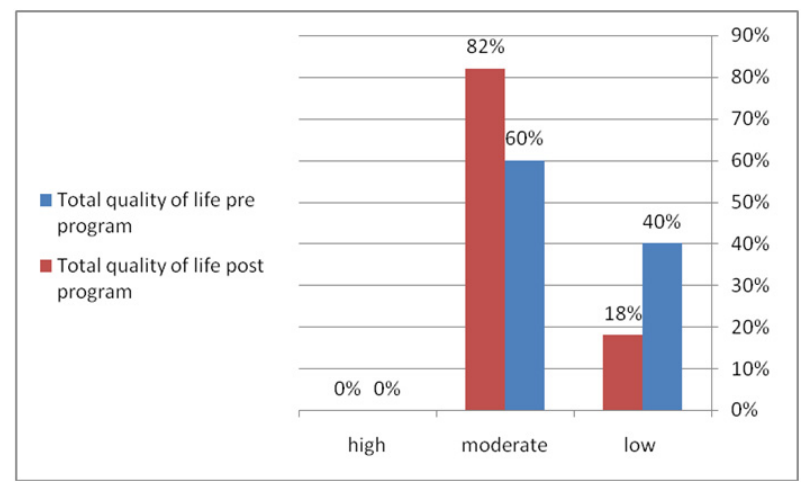

Figure 2. Total QOL pre-intervention to post-intervention

Table 2. The risk factors of hypertension and dyslipidemia of the studied subjects pre and post nursing intervention $(\mathrm{N}=100)$

\begin{tabular}{|c|c|c|c|c|c|c|}
\hline \multirow{3}{*}{ Patients' risk factors } & \multicolumn{4}{|c|}{ Study group } & \multirow{3}{*}{$\chi^{2}$} & \multirow{3}{*}{$p$-value ${ }^{*}$} \\
\hline & \multicolumn{2}{|c|}{ Pre-intervention } & \multicolumn{2}{|c|}{ Post-intervention } & & \\
\hline & $\mathbf{N}$ & $\%$ & $\mathrm{~N}$ & $\%$ & & \\
\hline Heredity factors & & & & & 70.380 & .732 \\
\hline - Yes & 41 & 41 & 41 & 41 & & \\
\hline - No & 59 & 59 & 59 & 59 & & \\
\hline Smoking & & & & & 14.780 & .001 \\
\hline - Yes & 36 & 36 & 29 & 29 & & \\
\hline - No & 64 & 64 & 71 & 71 & & \\
\hline Eating fatty food & & & & & 24.770 & .000 \\
\hline - Yes & 44 & 44 & 30 & 30 & & \\
\hline • No & 56 & 56 & 70 & 70 & & \\
\hline Salt on diet & & & & & 67.440 & .000 \\
\hline - Without & 18 & 18 & 30 & 30 & & \\
\hline - Small & 12 & 12 & 10 & 10 & & \\
\hline - Little & 45 & 45 & 36 & 36 & & \\
\hline - A lot of & 25 & 25 & 14 & 14 & & \\
\hline Depression & & & & & 137.840 & .000 \\
\hline - Yes & 75 & 75 & 30 & 30 & & \\
\hline - No & 25 & 25 & 70 & 70 & & \\
\hline
\end{tabular}

Note. ${ }^{*}$ Test of significance between pre and post intervention (chi square test) 
Table 3. Correlation between the physiological measurement of the studied subjects pre-intervention to post-intervention $(\mathrm{N}=100)$

\begin{tabular}{|c|c|c|c|c|c|c|}
\hline \multirow{3}{*}{ Physiological measurement } & \multicolumn{4}{|c|}{ Study group } & \multirow{3}{*}{$t$-test } & \multirow{3}{*}{$p$-value ${ }^{*}$} \\
\hline & \multicolumn{2}{|c|}{ Pre-intervention } & \multicolumn{2}{|c|}{ Post-intervention } & & \\
\hline & Mean & $S D$ & Mean & $S D$ & & \\
\hline \multicolumn{7}{|l|}{ Blood pressure } \\
\hline - Systole & 159.34 & 0.432 & 134.55 & 0.865 & 18.001 & .000 \\
\hline - Diastole & 90 & 5.518 & 84.22 & 5.562 & 153.891 & .000 \\
\hline Weight & 87.890 & 5.456 & 84.930 & 5.518 & 153.911 & .000 \\
\hline
\end{tabular}

Note. ${ }^{*}$ Test of significance between pre-intervention to post-intervention using paired sample $t$-tests

Table 4. Correlation between the laboratory results of the studied subjects pre-intervention to post-intervention $(\mathrm{N}=100)$

\begin{tabular}{|c|c|c|c|c|c|c|}
\hline \multirow{3}{*}{ Laboratory result } & \multicolumn{4}{|c|}{ Study group } & \multirow{3}{*}{$t$-test } & \multirow{3}{*}{$p$-value } \\
\hline & \multicolumn{2}{|c|}{ Pre-intervention } & \multicolumn{2}{|c|}{ Post- intervention } & & \\
\hline & Mean & $S D$ & Mean & $S D$ & & \\
\hline 1-Serum cholesterol & 256.390 & 0.24 .161 & 199.460 & 26.580 & 75.039 & .000 \\
\hline 2-Serum triglycerides & 172.240 & 8.877 & 143.130 & 12.360 & 155.797 & .000 \\
\hline 3-SerumLDL cholesterol & 118.020 & 11.084 & 96.550 & 10.214 & 94.525 & .000 \\
\hline 4-SerumHDL cholesterol & 36.520 & 5.252 & 47.300 & 8.618 & 54.88 & .000 \\
\hline
\end{tabular}

Note. ${ }^{*}$ Test of significance between pre-intervention to post-intervention (paired sample $t$-test)

Table 3 clarifies that there is a highly statistically significant reduction of the mean score of SBP, DBP, and weight from pre-intervention to post-intervention $(p=.000)$. This indicates an improvement of the SBP, DBP and weight following the nursing intervention.

Table 4 indicates that there is a highly statistically significant reduction of the mean score in the lipid profiles that include (serum cholesterol (total), serum TGs, serum LDL cholesterol, serum HDL) $(p=.000)$ from pre-intervention to post- intervention. This indicates an improvement of the lipid profiles after the nursing intervention.

Figure 2 shows improvement in the total QOL and all dimensions of the QOL instrument (physical, psychological, recreational and spiritual) after the nursing intervention with a highly statistically significant difference $(p=.000)$.

\section{Discussion}

Psychosocial stress, physical inactivity, fatness, and high sodium and alcohol consumption are considered as the risk factors of hypertension. ${ }^{[21]}$ Brook et al. reported that reduction of hypertension can achieved through application of interventions that include lifestyle modifications. ${ }^{[22]}$ In the present study, the main concern was to evaluate the effectiveness of the nursing intervention on cholesterol level and QOL among hypertensive patients with dyslipidemia.

\subsection{Sociodemographic characteristics of the studied sub- jects (see Table 1)}

The findings of the current study revealed that the subject's age was ranged between forty to less than fifty years old with mean of $36.21 \pm 4.96$ years. More than half were females, about two thirds were married, one-third graduated from secondary school and half of them were governmental employees. This result was in the line with Shaw et al., ${ }^{[23]}$ who concluded that the subject's age were ranged between thirtyseven to seventy-two with median age 58.3 years, about half of them were females.

In contrast, Irmak et al. ${ }^{[24]}$ noted that the mean age of hypertensive patients was $51.0 \pm 9.9$ years, $64.4 \%$ were females, $53.3 \%$ had graduated from primary school and $84.4 \%$ were married. Alsheikh et al. ${ }^{[25]}$ illustrated that more than half $(52 \%)$ of outpatients were female. Almustafa et al. ${ }^{[26]}$ reported that $66 \%$ of the cardio-metabolic risk patients were females with mean age $57.2 \pm 12.4$ years, and $65.2 \%$ were hypertensive. Finally, Theodorou et al. ${ }^{[27]}$ noted that more than half of the participants were employed males and the majority were married. This variation in socio-demographic data may be due to difference setting, time of data collection in the current study we collect the data at the morning where most males were in the working setting.

\subsection{The risk factors of hypertension and dyslipidemia (see Table 2)}

The result of the present study showed a highly statistical significant reduction in all risk factors of hypertension and dyslipidemia (eating fatty food, smoking, the amount of salt in the diet, depression) after the nursing intervention than before. About one third of the studied subjects had depression after the nursing intervention compared to more than two-thirds before the nursing intervention. This could mean that the program content was interesting to the patients and 
therefore they followed and applied the instructions given to them in the program accordingly. The symptoms of depression and lifestyle also improved among participants after the implementation of the nursing intervention. A similar result was supported by Duraimani et al., ${ }^{[28]}$ who observed reduced sodium and protein consumption among all subjects; while a large number of the health education group revealed reduced intake of calories, carbohydrates, and fats than the stress reduction group.

\subsection{The effect of the nursing intervention on the level of the knowledge of the studied subjects (see Figure 1)}

The current study revealed that about half of subjects presented good knowledge after the nursing intervention; compared to only twenty percent before the nursing intervention. These significant differences indicate the effectiveness of the nursing intervention and the interest of the participants to gain knowledge about their illness. This result was in line with study done by Kanchana and Nagarathnamma, ${ }^{\text {[29] }}$ who reported that the majority of the subjects had inadequate knowledge before the program; compared to about half of them had moderate knowledge after the program with statistically significant difference.

\subsection{The effect of the nursing intervention on the physio- logical measurements (see Table 3)}

The current study clarified that there was a highly statistically significant difference between pre-intervention and post-intervention regarding SBP, DBP, and weight. This may be due to the improvement of their knowledge following the instruction regarding diet and stress management. This result was also showed by Duraiman et al. ${ }^{[28]}$ who reported that relaxation increases the secretion of endorphin hormone and decreases the secretion of adrenalin hormone. It improves blood circulation and decreases anxiety and stress by creating a positive attitude and improving brain function. Relaxation also increases the cellular energy and one's confidence by relieving anxiety. Therefore, it balances the sugar and blood pressure. This result was also in agreement with Frisoli et al. ${ }^{[30]}$ who reported that lifestyle changes may postpone hypertension in non-hypertensive patients and diminish blood pressure in hypertensive patients which leads to reducing the frequency and doses of antihypertensive drugs. Also, these results were consistent with Shaw et al., ${ }^{[23]}$ who reported that both systolic and DBP improved after the intervention (3.68 $\mathrm{mmHg}$ for SBP, $1.56 \mathrm{mmHg}$ for DBP). More over, Irmak et al. ${ }^{[24]}$ noted a significant decrease in the mean systolic and DBP. In the same line, Rigsby ${ }^{[31]}$ and Hong ${ }^{[32]}$ reported improvement of the blood pressure among patients who modified an unhealthy lifestyle.
The results of the present study indicates a significant reduction in the lipid profile which includes (serum cholesterol (total), serum TGs, serum LDL cholesterol, serum HDL) pre-intervention to post-intervention. This indicates the effectiveness of the intervention on improvement of lipid profiles after the nursing intervention. These results were in the line with the findings of Shaw et al. ${ }^{[23]}$ who concluded that the nurse-managed protocols in the studies had a consistently positive effect on chronically ill patients, in addition the total cholesterol levels decreased by $0.24 \mathrm{mmol} / \mathrm{L}$, and LDL cholesterol levels decreased by $0.31 \mathrm{mmol} / \mathrm{L}$. Moreover, Bachen et al. ${ }^{[33]}$ found that serum cholesterol concentration and free fatty acids were increased following acute stress. On the other hand, chronic stress is associated with behaviors such as intake of high-fat meals, cigarette smoking and drinking alcohol, which in turn lead to disorders of lipid profile. In addition to Shahnam et al. ${ }^{[34]}$ concluded that the workers who stated that they had experienced difficulties in dealing with their job during the previous twelve months had a higher risk of suffering from dyslipidemia.

In contrast, Irmak et al. ${ }^{[24]}$ found that only TGs decreased in lipid values and there was no significant difference in total cholesterol; LDL cholesterol increased but HDL cholesterol decreased. Also, Park et al. ${ }^{[35]}$ illustrated that their study did not show any relationship between stress and high triglyceride levels.

\subsection{The effect of the nursing intervention on the QOL (see Figure 2)}

The current study presented significant improvement in the QOL after the nursing intervention. This may be due to providing emotional support to the patient through continuing social interaction with the researcher, encouraging the patient to cope with his illness through education, an learning relaxation techniques and assertiveness training.These results are in line with Theodorou et al, ${ }^{[27]}$ who found significant improvement in all dimensions of the QOL in follow-up measurements. Moreover, Park et al. ${ }^{[35]}$ found that health education and individual counseling was significantly effective in improving blood pressure, self-care behaviors, exercise self-efficacy, and medication compliance of hypertensive residents at a nursing home. Also, Mersal et al. ${ }^{[36]}$ reported that self- efficacy was significantly improved among a study group after implementation of lifestyle guidelines than control group.

\section{Conclusions}

This study concludes that the nursing intervention which includes walking exercise, adherence to a prescribed diet and medications, stress management, assertiveness training, and

ISSN 2324-7940 E-ISSN 2324-7959 
promoting emotional expression have a positive effect on blood pressure, cholesterol levels and QOL among hypertensive patients with dyslipidemia.

\section{Recommendation}

Based on this study it is recommended that the nursing intervention that includes of adherence to diet regimen, prescribed medication and performing physical exercise, stress manage- ment, assertiveness training should be integrated into the medical outpatient clinic to assist patients diagnosed with hypertension to cope with their illness and improve the QOL of hypertensive patients in this geographical loction.

\section{CONFlicts of InTEREST Disclosure}

The authors declare they have no conflict of interest.

\section{REFERENCES}

[1] Ministry of Health and Population [Egypt], El-Zanaty and Associates [Egypt], and ICF International. Egypt Health Issues Survey. Cairo, Egypt and Rockville, Maryland, USA. 2015.

[2] Wu S, Huang Z, Yang X, et al. Cardiovascular events in a prehypertensive Chinese population: a four-year follow-up study. International Journal of Cardiology. 2013; 167(5): 2196-9. PMid: 22805539. https://doi.org/10.1016/j.ijcard.2012.05.123

[3] WHO and ARE. Ministry of Health \& Population: Egypt National STEPwise. Survey of Non Communicable Diseases Risk Factors. 2011-2012.

[4] World Health Organization. Global status report on noncommunicable diseases. Geneva. 2011.

[5] Dalal J, Padmanabhan N, Jain P, et al. LIPITENSION: Interplay between dyslipidemia and hypertension. Indian J Endocrinol Metab. 2010; 16(2): 240-245.

[6] American Academy of Family Physicians. Primary Prevention of CVD: Treating Dyslipidemia. BMJ. 2011; 83(10): 1207-1208.

[7] Calvo C, Sanchez-Chaparro A, Valdivielso P, et al. The relationship between job stress and dyslipidemia. Scandinavian Journal of Public Health. 2013; 41(2): 142. PMid: 23282939. https: //doi.org/10.1177/1403494812470400

[8] Mori A, Beilin J. Long-chain omega 3 fatty acids, blood lipids and cardiovascular risk reduction. Current Opinion in Lipidology. 2011; 12: 11-7. https://doi.org/10.1097/00041433-20010 2000-00003

[9] Abdul-Rahman R. Clinical practice guidelines, Management of Hypertension, (4th Edition), Malaysia. 2013. Available from: www.moh . gov.my

[10] Wong D, Lopez V, Tang S, et al. Prevalence, treatment and control of combined hypertension and hypercholesterolemia in adults in the USA. Am J Cardiol. 2006; 98: 204-8. PMid: 16828593. https://doi.org/10.1016/j. amj card.2006.01.079

[11] World Heart Federation. Cardiovascular disease risk factors. 2016. Available from: http://www.world-heart-federation.org/ cardiovascular-health/heart-disease

[12] World Heart Federation. 2016. Available from: http: //www. world-heart-federation.org/cardiovascular -health/stress

[13] Endocrinologists AAOC. The American Association of Clinical Endocrinologists Medical Guidelines for the Management of Diabetes Mellitus: the AACE system of intensive diabetes self-management2000 update. Endocrine Practice. 2000; 6(1): 43-84.

[14] Margolis L, Ray M, Van Horn L, et al. Effect of calcium and vitamin D supplementation on blood pressure: The women's health initiative randomized trial. Hypertension. 2010; 52: 847-855. PMid: 18824662. https://doi.org/10.1161/HYPERTENSIONAHA.108.114991

Published by Sciedu Press
[15] WHO. Global Health Observatory (GHO) data. Raised blood pressure. 2016.

[16] Kishore J. National Health Programs of India, Century Publications, New Delhi, India, 11th edition. 2014.

[17] Fedder O, Koro E, L'Italien J. New National Cholesterol Education Program III Guidelines for Primary Prevention Lipid - Lowering Drug Therapy. Circulation. 2002; 105: 152-156. PMid: 11790693. https://doi.org/10.1161/hc0202.101971

[18] Eckel RH, Jakicic JM, Ard JD, et al. AHA/ACC Guideline on Lifestyle Management to Reduce Cardiovascular Risk. J Am Coll Cardiol. 2013; 63(25): 1-17.

[19] Padilla G, Grant M. Quality of life as a cancer nursing outcome variable: Adv. Nurs Sci. 1985; 8(1): 45-60. https://doi.org/10.1 097/00012272-198510000-00007

[20] Kandel F. Quality of life among cancer bladder patient with different diversionk, unpublished master thesis. Faculty of Nursing; Cairo University. 1998.

[21] Wang M, Moran E, Liu J, et al. A meta-analysis of effect of dietary salt restriction on blood pressure in Chinese adults. Glob Heart. 2015. https://doi.org/10.1016/j.gheart.2014.10.009

[22] Brook D, Appel J, Rubenfire M, et al. Beyond medications and diet: alternative approaches to lowering blood pressure: a scientific statement from the American heart association. Hypertension. 2013; 61: 1360-1383. PMid: 23608661. https://doi.org/10.1161/HYP. Ob013e318293645f

[23] Shaw RJ, Mcduffie JR, Hendrix CC, et al. Effects of nurse-managed protocols in the outpatient management of adults with chronic conditions: a systematic review and meta-analysis. 2014; 161(2): 113-121.

[24] Irmak Z, Duzoz G, Bozyer I. The effectiveness of a follow-up program on blood pressure and cardiovascular risk factors for hypertensive patients. Australian Journal of Advanced Nursing A Quarterly Publication of the Royal Australian Nursing Federation. 2010; 28(2): 60-66.

[25] Alsheikh-Ali A, Omar M, Raal F, et al. Cardiovascular risk factor burden in Africa and the Middle East: The Africa Middle East Cardiovascular Epidemiological (ACE) Study. PLoS ONE. 2014; 9(8): e102830. PMid: 25090638. https://doi.org/10.1371/journa 1.pone. 0102830

[26] Almustafa B, Almobarak A, Hejlis M, et al. High blood pressure management in qatif primary care: seven years data. Journal of $\mathrm{Hy}$ pertension. 2015; 33: 10-15. https://doi.org/10.1097/01.h jh. 0000468157.74864 .74

[27] Theodorou M, Kaitelidou D, Galanis P, et al. Quality of Life Measurement in Patients with Hypertension in Cyprus. Hellenic J Cardiol. 2011; 52: 407-415. PMid: 21940288.

[28] Duraimani S, Schneider R, Randall O, et al. Effects of Lifestyle Modification on Telomerase Gene Expression in Hypertensive Patients: 
A Pilot Trial of Stress Reduction and Health Education Programs in African Americans., PLoS ONE. 2015; 10(11): e0142689. PMid: 26571023. https://doi.org/10.1371/journal.pone.01426 89

[29] Kanchana G, Nagarathnamma M. Effect of structured teaching programme on patient attending cardiology outpatient department. Nurs. India. 2009; 10(10): 4-6.

[30] Frisoli M, Schmieder E, Grodzicki T, et al. Beyond salt: lifestyle modifications and blood pressure. Eur Heart J. 2011; 32: 30813087. PMid: 21990264. https://doi.org/10.1093/eurheart j/ehr379

[31] Rigsby D. Hypertension Improvement through healthy lifestyle modifications. ABNF J. 2011; 22(2): 41-43. PMid: 21675668.

[32] Hong S. Evidence-based nursing practice for health promotion in adults with hypertension: a literature review. Asian Nurs Res. 2010
4(4): 227-245. https://doi.org/10.1016/S1976-1317(11)6 0007-8

[33] Bachen A, Muldoon F, Matthews A, et al. Effects of hemoconcentration and sympathetic activation on serum lipid responses to brief mental stress. Psychosom Med. 2002; 64(4): 587-94200-38-C.

[34] Shahnam M, Roohafza H, Sadeghi M, et al. ARYA Atheroscler. The Correlation Between Lipid Profile and Stress Levels in Central Iran: Isfahan Healthy Heart Program Fall. 2010; 6(3): 102-106.

[35] Park H, Chang H, Kim J, et al. Patient-tailored self management intervention for older adults with hypertension in a nursing home. $\mathbf{J}$ Clin Nurs. 2012; 22: 710-722. https ://doi.org/10.1111/j.13 65-2702.2012.04236.x

[36] Mersal F, Mersal N. Effect of Evidence Based Lifestyle Guidelines on Self Efficacy of Patients with Hypertension. Int J Curr Microbiol App Sci. 2015; 4(3): 244-263. 